\title{
MEDICAL BOTANY.
}

$+$

581,63

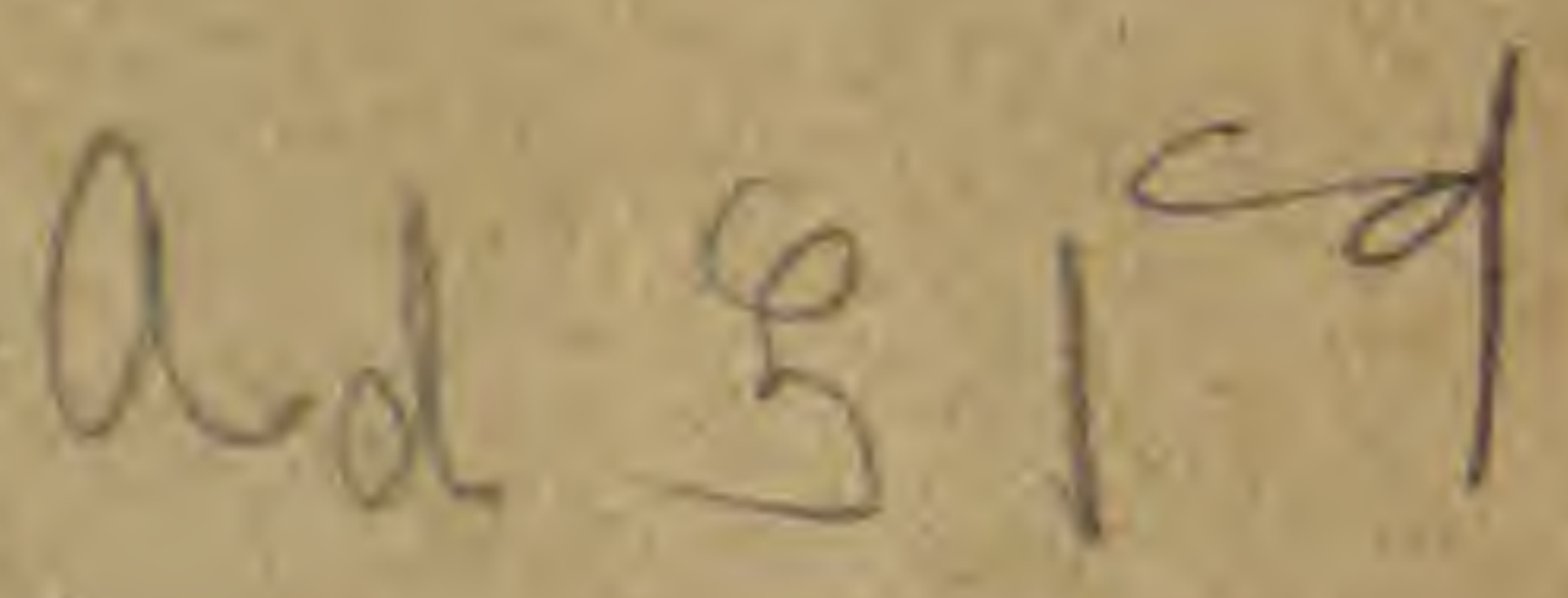

Presented to the Section on Materia Medica, Pharmacy and Thera-

- peutics, at the Forty eighth Annual Meeting of the American Medical Association, held at Philadelphia, Pa., June 1-4, 1897.

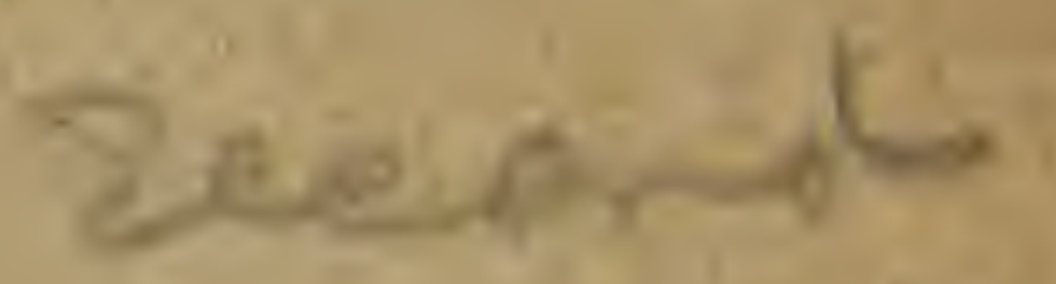

BY WILLIAM TRELEASE, Sc.D. DIRECTOR OF THE MISSOURI BOTANICAL GARDEN,

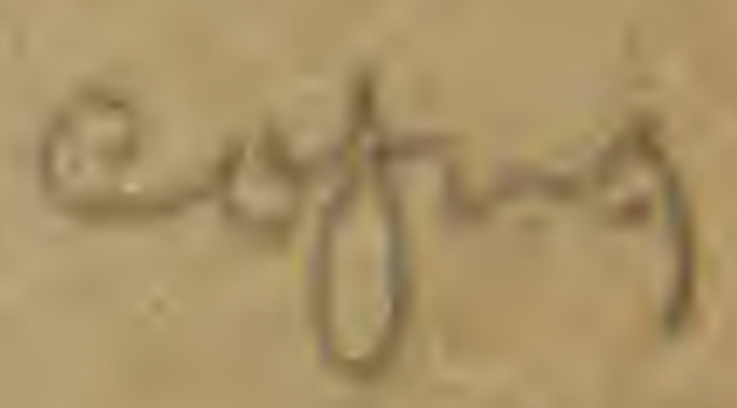

ST. LOUI8, MO.

REPRINTED FROM THE

JODRNAL OF THE AMERICAN MEDICAL ASSOCIATION.

SEPTEMBER 4, 1897.

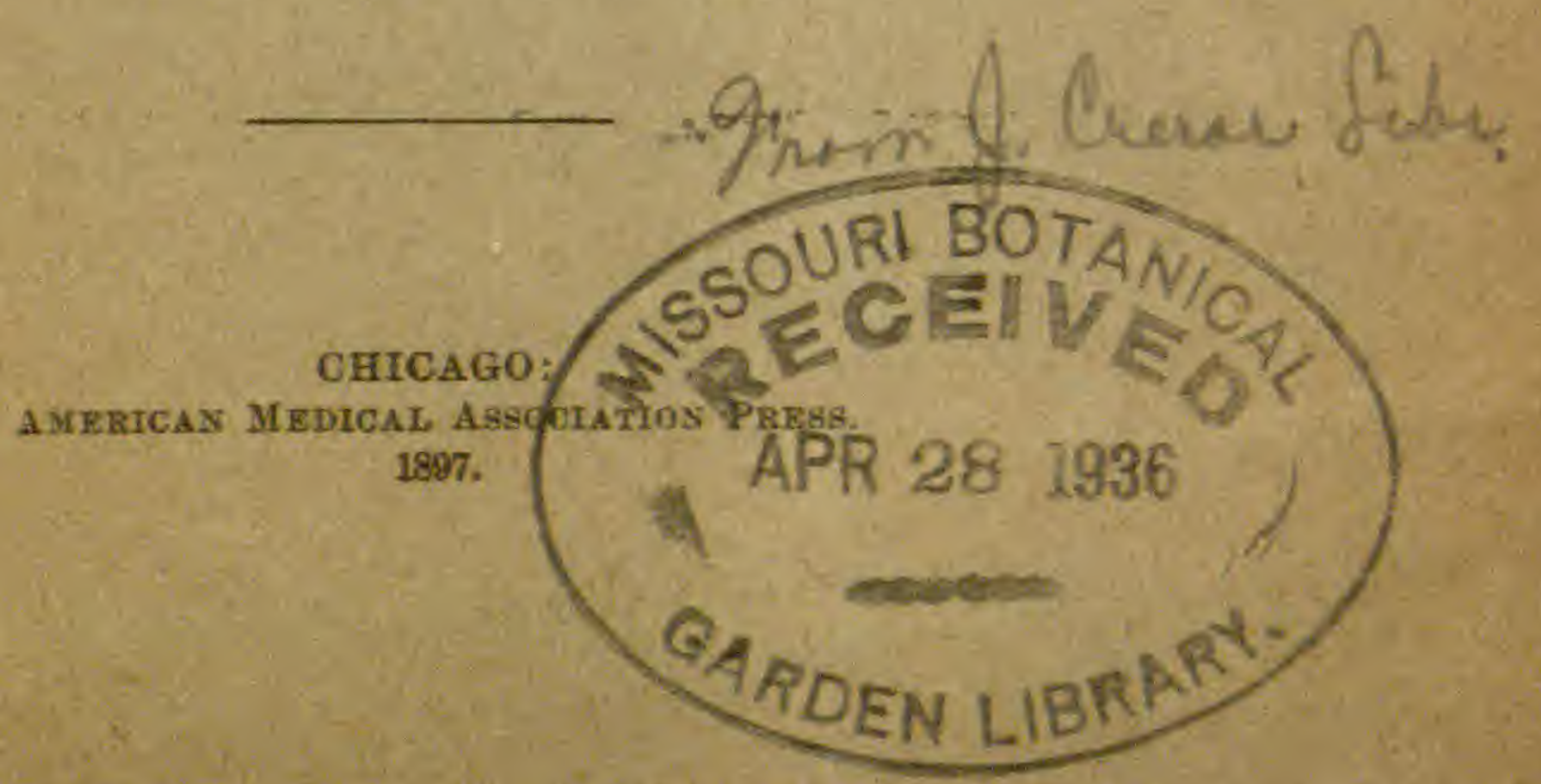




\section{MEDICAL BOTANY.}

BY WILLIAM TRELEASE, Sc.D.

Prior to emergence from its nameless,barbaric state, the human race was undoubtedly versed in botany of a strictly practical kind. All omnivorous and vegetable feeding creatures distinguish between wholesome and poisonous plants. Even the butterfly selects the right species on which to deposit its eggs, often from among others that to our eyes are almost identical with it. As our race has advanced in civilization, owing its progress to a more and more rigid division of labor, with the attendant and ever increasing specialization by which each piece of the great machine does its work more perfectly, yet more and more completely loses its direct touch with all but a few of the other parts, most men have lost much of what was at first common to all; and this is, perhaps, quite as true of a knowledge of plants as of anything else. As we go from the higher to the more primitive civilization of the present time, we approach by successive steps toward what was at one time characteristic of the entire human race. The country boy has names for most of the plants that the city boy passes by perhaps with a vague notion that they have no names, and he knows abundant uses for many of them. Many is the time that I have hunted sweet cicely and pipsissewa, wintergreen and sarsaparilla in the Connecticut woods; and hoarhound and boneset, yarrow and wormwood are still to be found in the kitchen or the attic of most New England farmhouses. In less favored parts of the globe, where the farmer is a peasant, and the peasant often little better than a clodhopper, this sort of knowledge is even more extensive and widespread. 
It is said that the mongoose, when bitten by a cobra, runs at once into the jungle and seeks out a plant which it recognizes and eats as an antidote. Whatever the actual knowledge and its value may be, it is certain that every primitive community believes in the healing virtues of many plants and makes use of them for these supposed virtues; and this sort of knowledge was undoubtedly the first that came after the power of discriminating between plants that are edible and those that are not. Among many people considerably removed from the aboriginal state, even today, the only conception of a collection of herbarium specimens is that they are for some medicinal use.

Recently in turning to the periodical cases in our library for a reference, my eye fell on a nearly forgotten volume of the Botanic Advocate, published in New Haven in 1843, and on opening it I found it to bear the legend: "The tree of life yielded her fruit every month, and the leaves of the tree were for the healing of the nations." The journal was published by the Connecticut Botanic Society, and I observed that it contained a series of three articles on the subject assigned me, "Medical Botany," the titles of which were "Lobelia Inflata," "Capsicum Annum" and "Myrica Cerifera." Lobelia and calomel were mentioned on nearly every page and appeared in the titles of many of the articles. It is probably unnecessary to say that the journal and the society of which it was the organ were Thomsonian! Independently of the herbalists, however, the botanists of a generation or two ago were physicians, and M.D. today is not an uncommon suffix to the name of a botanist, so that the subject assigned to me would seem to be an especially appropriate one for a gathering of medical men.

A very large part of the remedies applied by the physician today are of vegetable origin, and this branch of materia medica is an important part of the course of study of a physician. But this, as above said, is the age of specialization; it is the age of drug- 
gists and prescription clerks, of triturates and fluid extracts, and of laboratory synthesis. Few, indeed, are the physicians who can make a tincture or an alkaloid salt as well or as cheaply as the druggist or the manufacturing chemist, and, under needful restrictions, the latter are turned to by the physician as certain to supply the things needed in a pure and assimilable form, and in any desired proportion. Even water for the physician's use, that was first employed as it came from the well, the cistern or the brook, then boiled before use, and then turned over to the druggist for distillation, so that it could be procured in a pure and safe form for critical purposes, is finally coming into the hands of people whose exclusive business is the distillation and purification of water. The materia medica, like one's clothing, is more and more something to be ordered outside rather than a legitimate subject for home manufacture.

And so it has come that the study of medical botany has today fallen to the pharmacist to a larger extent than to the medical student. $\mathrm{He}$, indeed, is expected to know his botany well. He need not be a vegetable physiologist or a mycologist, and karyokinesis may possibly be a process of which he never heard, but in certain lines he must be a botanist. As a result, we find studies of this kind omitted from the medical curriculum proper and given place in that branch of medical study which has come to have a name and a place of its own-pharmacy.

Whether taught in the medical school or the school of pharmacy or the school of botany, the knowledge which the collector and the manufacturer of drugs needs is of the most practical and useful character. A knowledge of the affinities of plants will very often lead the manufacturer to experiment with species related to those which yield useful products. You are all familiar with the various cinchonas and their relative quininproducing properties. But in the main the knowledge which is needed is that which enables one surely to distinguish one certain plant in all its forms from all 
other plants. Every few years the drug trade is exercised over substitutes offered more or less honestly by collectors and jobbers. It is only a short time since cascara sagrada, the bark of Rhamnus Purshiana, was replaced very considerably by the bark of a related species, Rhamnus Californica, the latter of much inferior quality. It is also only a few years since the trade journals contained an extensive description of the substitution of the roots of Polygala alba for the senega snakeroot, Polygala Senega. Not many years ago, a sample of tansy which was submitted by a large wholesale house proved, probably as the result of a clerical blunder, to be pansy.

The direct solution of problems of identity like the preceding is the closest link between botany and pharmacy, the most obvious medical botany. It is a branch of the study of vegetable pharmacognosy. The last instance mentioned is a very simple one. The merest tyro could detect the mistake and guess pretty closely at the cause for it; but in the other cases a discrimination between the things to be compared proved decidedly more difficult.

As they come to the wholesaler and the manufacturer, drugs are apt to occur in the form of more or less fragmentary root, rootstock, bark, leaf, flower, fruit and seed. Only rarely, as in the case of opium, are the active principles collected to any great extent freed from the parts of the plant which produces them. Hence, in the great majority of cases, the medical botanist is expected to accurately name certain parts of fairly well-known plants.

It has, unfortunately for this purpose, been the habit of descriptive botanists to aim at as brief a diagnosis of each species as possible, and to use those characters which most surely and most readily serve to separate it from its congeners; or else, as is the case with much modern work, what are felt to be the less variable and consequently the surest and most permanent characters have been taken as the basis of classification, many of the more obvious features being left entirely unde- 
scribed. The result is that a person who uses the ordinary manuals of botany, unless he is quite expert as a botanist, requires flowering or fruiting specimens as a preliminary for the determination of their names, and very much of the botany taught in schools and colleges, being based on and preparatory to the use of these manuals, is confined to a study of the characters employed in them.

Medical botany, if well done, must start from a somewhat different standpoint. It by no means follows that a plant which can be determined by aid of the usual manuals only when it is represented by perfect flowering and fruiting material, can not be known with almost or quite as great certainty when neither flowers nor fruit are present. Except in certain genera, like the oaks and plums, the trees and shrubs of our flora may be known with quite as much certainty in the winter when destitute of flower and fruit, and even foliage, as in the summer season; but in the absence of manuals based on their winter characters, this knowledge is possible only as the result of individual observation and investigation, based primarily on a knowledge of the species derived while their summer characters are present; and the same is true, to a greater or lese extent, of all of the fragmentary, or as the botanist would call it, imperfect material that passes through the hands of the medical botanist.

The characters which the latter makes most use of are histologic characters. Where sufficiently large fragments of root or rootstock, leaf or fruit or seed occur, these may of course be used, being subject to whatever preparation is necessary to bring them into a condition fit for comparison with either living or preserved authentic specimens; but it is only exceptionally that a superficial comparison is sufficient. Usually the distribution of the woody tissues and ducts and of the bast fibers within the specimen, the occurrence of resin passages, oil cells or latex tubes, the character and the distribution of stomata and palisade cells in the leaf, the occurrence or absence of 
pubescence and superficial glands, and the structure and grouping of the hairs and the structure of the seed shell have to be looked into. Sometimes, also, it is necessary to test the degree of lignification of certain cell-walls, to determine the nature of secretions, and to examine, both morphologically and chemically, the starch contained in the specimen, which is compared in each of these respects with authentic standards.

Evidently this practical botany of medicines rests upon a more or less intelligent conception of botanic classification, but is itself the application of a special skill. Quite recently a professor of pharmaceutic botany in one of the leading colleges of the country published a laboratory manual which may be held to represent his ideas as to what should be taught in preparation for it. A general knowledge of the parts of the plant, root, stem, leaf, etc., and of each of the principal tissues of the higher plants, is accompanied by a rather thorough examination of several plants of medicinal value or related to medicinal species. As thorough a knowledge as may be of a few plants is sought for, instead of a little knowledge concerning a great many, in the expectation that on this the student will subsequently build an equally thorough knowledge of all of the plants coming within the range of his observation. Not many years since another successful teacher of the same subject laid down the essential thing as being "that the course should be sufficiently comprehensive to equip the student if he desires at its conclusion to pursue further investigation of the study by himself, that is without all assistance other than books such as manuals, classbooks, floras, etc." To accomplish this he divides his classes into sufficiently small sections to place specimens of each subject taken up in his lectures into the hands of all pupils, keeping before their eyes at all times on the walls of the room, a carefully labeled set of specimens illustrating the same things, and closing his course by an exercise in which a lot of mixed, 
unnamed material is placed on the lecture table and sorted out by the professor and students, the characters utilized being indicated step by step during this exercise.

Here, if anywhere, object teaching is essential, and each of these courses is taught as a series of object lessons. Gross characters are made out by the aid of the naked eye and simple magnifying glasses, but for others the compound microscope is brought into requisition and some of the pharmaceutic schools have as a part of their curriculum a regular course in microscopy. Unless it be biology, no word is more abused than this; but for our purpose a sufficient working knowledge of the optic and mechanical parts of the microscope and ability to make serviceable temporary and permanent preparations, is treated as of far greater value than the ability to resolve difficult test objects and to run an unimpeachable ring of Brunswick black or shellac. All that is useful in the technique of the zoologist, the botanist and the embryologist, is utilized to get serviceable sections cut with intelligence at a point calculated to show representative structure, and the skill of the chemist is made to yield, under the cover-glass, reactions as characteristic in their way as those obtained in the test-tube or before the blowpipe. Equipped in this way, the student is able to determine those characters afforded by his material which enable him to say with certainty that it is or is not the same as a standard specimen of the thing to be compared with. Primarily he is called on to recognize this identity or difference in comparison with the plant that the material is supposed to represent. If it be different the question as to what it really is is only a secondary one, and as his knowledge increases he becomes more and more able to answer these accessory questions.

A good description is more available for use than a poor specimen, and the time is coming when this, as well as each other branch of technical botany, will be equipped with manuals employing the characters 
which are available in the class of material that must be studied. Perhaps the progress of American systematic botany has been retarded more by the easily acquired habit of naming new specimens by matching them in the herbarium than in any other way; and the best workers, now that monographs are increasing in number, turn first to a monograph and determine a specimen by the aid of the descriptions before going to the herbarium. But what is a good description today may be a very poor description five years from now, owing to the discovery of new material influencing the limitation of species. Hence a specimen is always potentially better than a description, since the former is the thing itself, while the latter is only a more or less subjective interpretation of it, and in medical botany, as in general botany, the herbarium is of prime importance.

The medical or pharmaceutic herbarium should differ from the general herbarium in containing only medicinal plants and their nearest allies. One familiarizes himself with an herbarium of a thousand sheets where he is utterly at sea in a collection of a quarter of a million specimens. The specimens contained in this technical herbarium should be perfect from all points of view:- good in the sense of the ordinary botanist as representing the technical characters which he uses in classifying each plant; good from the standpoint of the person who does not know general botany in representing every part of the plant which he may find in a disconnected condition and wish to compare; good from the standpoint of the histologist as affording usable material for sectioning and microchemistry; and good from the standpoint of the investigator in offering abundant material for study and comparison. Where the woods can be turned to by the student the herbarium specimens are easily supplemented when needed by freshly gathered material; but manufacturing pharmacists, like other manufacturers, drift into large cities where this is often inconvenient or impossible. Not long ago it was said in one of the leading 
druggists' journals that "the pharmaceutic profession more than almost any other, is interested in the proposition to establish a great botanic garden (referring to the then proposed New York garden). As scientific principles become more and more extensively incorporated into the practice of pharmacy, there is increased recognition of the necessity for a practical acquaintance with the sources of our drugs. This does not of necessity imply an extensive knowledge of theoretic botany, desirable as that is, but a thorough personal acquaintance with medicinal plants is of the greatest value to him who must daily discriminate against substitutions, adulterations, inferior varieties and collections and deteriorated samples. The ideal opportunity for cultivating this acquaintance is in the botanic garden, where we have brought together for immediate comparison the doubtful species under consideration in a living state, and where the characters thus observed can be followed up closely in the herbarium and materia medica collections forming adjuncts to the garden." Besides what can be preserved in the herbarium proper and the garden, the reference collection ought to contain standard material of all drugs in their crude form, so that any changes in appearance which the specimen under study may have undergone during its preparation will be likely to be matched by a corresponding change in the standard; and besides the museum material here referred to, which is most readily utilized by the investigator if kept boxed in immediate connection with the herbarium sheets, a set of histologic preparations ought to be made, representing not only the tissues of each officinal plant from authentic specimens, but also such preparations as can be made from the fragmentary drug. of which good sections are often obtained with difficulty, while the mode of fragmentation is sometimes characteristic.

Today nearly all students are taught not only to observe, but to record their observations, both in writing and by means of sketches. The medical bot- 
anist, perhaps more than most others, is likely to be benefited by forming this habit. A sketch made while the study is fresh in one's mind, somewhat idealized, not by the introduction of fanciful details but by the omission of confusing structures which one sees in all preparations, renders the future examination of a slide much easier and the conclusion drawn from a comparison with it more certain. I should therefore sketch the essentials of every preparation so preserved, and while the matter is fresh in one's mind a brief memorandum is easily written in connection with the sketch, describing differences between related things that may be transient in the slide or liable to be overlooked.

Medical botany, therefore, as a technical study for the manufacturing pharmacist and collector, and to a less extent for the dispensing druggist, but hardly for the medical man, in my mind is really a minute acquaintance with each plant used in medicine, with each of its parts in the form in which they are employed for the extraction of the drug as finally used; and it is properly learned by a course of study limited to very nearly the lines sketched above. Having reached this point, the botanist very properly, if time permits, extends his knowledge of general botany. Before this point, if he know the meaning of a generic and a specific name, of a natural family and a variety, he is enough of a botanist to do his work well.

To the physician of today, medical botany, which only a few years ago seemed to be passing from his hands, is returning in twofold form, but it is doubtful if the great majority of physicians are justified in dipping very far into it. Occasionally poisoning by eating certain toadstools, or roots of a few umbellifers, demands a certain amount of botanic knowledge, but I take it that in practice the suspicion of this poisoning is as practically useful as the actual knowledge of the plant which has caused it. The dermatologist, more than the general physician, is called on to recognize causes for dermal manifesta- 
tions which he often traces to the use of food of one sort or another, which in some cases the idiosyncrasy of the patient reacts to in rather a marked way, and it is only a few years since a professor in the Harvard Medical School published an exhaustive treatise on the plants which produce such effects. A few plants, like the poison ivy, are very pronounced external irritants. But so far as practical purposes are concerned, the physician needs to know to what to ascribe certain manifestations of this sort, very much as he needs to know the effect of certain drugs, rather than to have a botanic knowledge of the irritant.

With the growing knowledge of bacteria, however, a more directly necessary branch of medical botany seems to be opening up. It is not necessary for the physician to know all bacteria, perhaps hardly necessary to know any large number of pathogenic species; but tubercle, leprosy, cholera, and certain other diseases of frequent occurrence, are so clearly marked by the occurrence of bacteria in or about the diseased tissues, that a diagnosis is often made with certainty only after a bacteriologic examination has been made. The Widal test for typhoid fever now has come into general use, and in the case of cholera and diphtheria it is, I believe, generally recognized that an easily made pure culture of bacteria from the patient affords the surest and quickest information as to the positive occurrence of the disease.

Today I suppose that there is not a good medical school in the country which has not a well equipped bacteriologic laboratory. The teaching needed for this branch of medical botany, like that needed for the older medical botany, which is now more properly regarded as pharmaceutic botany, ought to be of the most directly practical kind. A knowledge of methods first and of facts afterward is what is demanded. Some bacteria, the ordinary aerobic species, are so easily isolated and grown in pure cultures that the means of doing this ought to be at the hand of every physician, though I observe that certain boards of 
health are now undertaking to supply the apparatus and culture media needed for diphtheria work, so as to reduce the practitioner's part to the minimum of manual manipulation. The preparation and examination of slides offers little difficulty to the medical student who is already equipped with a knowledge of microscopic and histologic technique, so that he readily learns the special treatment needed for this sort of work. Here, as in pharmaceutic botany, the reference to authentic descriptions and authentic material becomes more and more necessary in proportion as one passes from hasty diagnosis to scientific investigation; but just as the dispensing druggist is becoming more and more freed from the routine of botanic examination, so the exhaustive study of the etiology of any germ disease is passing more and more from the physician to the medical bacteriologist who specializes in this direction, and whose training, built on a broad clinical experience, is supplemented by a continuation of the preparatory studies which the ordinary physician is obliged to make. The difference is in degree, however, rather than in kind. 